\title{
Universal Application of Yoga for Peace and Harmony
}

\author{
Ajay Bhardwaj* \\ Department of yoga and health, DSVV, Dehradun, India
}

Submission: March 07, 2019; Published: May 28, 2019

*Corresponding author: Ajay Bhardwaj, Department of yoga and health, DSVV, Dehradun, India

\begin{abstract}
The present study aims to analyze the need and importance of yoga for social and global transformation. Yoga works on one's body, mind and spirit. Therefore, it is known as the global art. If our body, mind and soul are healthy and harmonious, we can bring health and harmony to the society, nation and the globe by being a healthy and harmonious organ of the global body of humanity. Yoga is universal in appeal and applicable to the world humanity irrespective of caste, creed, religion or nation. Today on global level we are witnessing several problems like terrorism, religious fanaticism, racial hatred, global warming etc. It is yoga which can give permanent solution to these global problems. There is the need of the moral, ethical and cultural refinement of the individual personality on a worldwide scale by spreading and practicing the age-old philosophy of yoga.
\end{abstract}

Keywords: Yoga; Social; Global; Transformation; Refinement

\section{Introduction}

Yoga is the ancient cultural and spiritual heritage of India. It has come down from the traditions of saints, seers, sages and Rishis for the individual, society, and the whole humanity. Yoga is the most glorious gift of INDIA to the world. Yoga was a divine gift revealed to the ancient sages so that mankind could have the opportunities to realize its divine nature. Generally, the teachings of yoga were passed on from Gurus to their disciples. Through personal experiences, self-realized Yogis were able to guide sincere aspirants. It was slowly evolved and developed by the ancient and modern seers, yogis during different periods. In Vedic period Vedic Seers laid the foundation of Yoga with their extensive experiments. Self-realization is possible only through the union (Yoga)-this has been the universal message of Upanishads in Upanishadic period. In the 6th century B.C. Lord Buddha's influence brought the ideals of meditation to the fore. Credit goes to Maharshi Patanjali for codifying Yoga (300 B.C.) In the 8th century Adi Shankaracharya enlightened the light of Gyan Yoga (Yoga of Knowledge). In the middle age's saints like Kabir, Tulsi, Meera, Ravi das, Chaitanya Mahabrabhu etc. flowed the different streams of Yoga such as Yoga of Knowledge, Yoga of action and Yoga of devotion. In the medieval period Hath Yoga was evolved and became very popular. Guru Gorakhnath, Swami Swatmarama,Gheranda Rishi were the great Hath Yogis. In modern period great yogis like Ramkrishna Paramhansa, Swami Vivekananda, Maharshi Aurobindo, Maharshi Raman, Swami Shivananda, Paramhansa Yogananda, Yugrishi Sri Ram Sharma Acharya, Swami Ramdev, etc. made a remarkable contribution to the development and divine tradition of Yoga. Today in the 21st century we are witnessing the grand celebration of Yoga worldwide as International Day of Yoga on every 21st of June.
The word Yoga is derived from the Sanskrit word "yuj"meaning to yoke, join or unite. It embodies the unity of body, mind and spirit; thought and action; restraint and fulfillment; and harmony between man and nature. It is not about exercise but to discover the sense of oneness with oneself, the world and nature. By changing our lifestyle and creating consciousness, it can help in bettering our well-being. It is the integration of one's thoughts, words, and actions to create a sense of wholeness. It is about exploring one's inner world and becoming more aware of the world around us. By the practice of Yoga, our consciousness expands as wide as the universe and far beyond. All the systems of Yoga practiced up to now had almost the same goal and purpose. There are different paths of yoga such as Raj Yoga, Hatha Yoga, Mantra Yoga, Laya Yoga, Karma Yoga, Gyan Yoga and Bhakti Yoga. All these paths of Yoga lead to the same goal of self-realization.

The oldest use of the word yoga as found in the Vedic literature [1] (i.e. Rigveda5.5.81.1), Atharavaveda 6-91,1) indicates the union of the individual consciousness with universal consciousness. [2] Yoga has been being practiced since time immemorial but credit goes to Maharshi Patanjali for systematizing and keeping the nectar of yoga in the form of sutra in a jar popularly known as the yoga sutra. No doubt, the ultimate goal of yoga is self-realization but yoga at the same time paves the way for physical, mental, spiritual and social well-being as well. While yoga gives immense benefits to the body, mind and spirit of the individual, society gets transformed into a healthy, harmonious, peaceful, prosperous and blissful society.

The yoga makes one aware of his own true nature: who am I? And with this awareness the whole world changes. Swami 
Vivekananda very clearly remarks that" as the reflection of the moon on the sea is broken or blurred by the waves, so is the reflection of the Atman, the true self, broken by the mental waves. Only when the sea is stilled to mirror like calmness, can the reflection of the moon be seen, and only when the mind stuff, the chitta, is controlled to absolute calmness (through the practice of yoga, as Patanjali says yoga is the inhibition of mental waves) [3], and that when the mind is completely controlled, the seer is established in his own essential nature [4]. "Needless to say, that for a healthy and beautiful society, energetic and active human beings are necessary. Yoga is therefore applicable not only in the personal life but in the social and global life as well. A person is the smallest unit of the society therefore, when an individual is shaped and nurtured with human values through the practice of the yoga, a society of tolerant, truthful, non-violent, honest and caring individuals begins to build from that very moment.

\section{Role of Yoga in Personal Transformation}

Yoga employs a broader holistic approach that focuses on teaching people a new lifestyle, a new way of thinking and way of being in the world. The role of Yoga for healthy and happy living has been recognized even by scientists all over the world. Yoga establishes harmony between mind, body and spirit. A person who does not possess physical, mental, spiritual and social well-being is a danger for himself and society as well. Today, the current society is the over flooded with evil tendencies like violence, corruption, selfishness, and countless immoral and inhuman activities. Why? Because a person living in society is not mentally, socially and spiritually healthy. He is deprived of moral values. He lacks clarity and understanding to act. So, he is baffled and confused. It is where yoga opens its door to help us. As the Gita 2-50 says: "yoga karmashu kaushalam "which implies that skill in action lies in yoga or the excellence in action is yoga. [5] Philosophers, psychologists and social scientists suggest the need to look within to investigate our thoughts and actions. Let us explore why the eight steps of Raj Yoga are an optimal approach for personal transformation. In Raj Yoga eight steps have been described by Maharshi Patanjali. They are Yamas, Niyama, Asana, Pranayama, Pratyahara, Dharna, Dhyan and Samadhi [6]. This yoga very scientifically begins with the emphasis on values through Yama and Niyama.

\section{Yamas}
a. non-violence
b. truthfulness
c. non-stealing
d. celibacy
e. non-possessiveness [7]

Nonviolence: (Ahimsa) means trying to be nonviolent toward all (animate and inanimate) in thought, word and deed. It teaches us to be sensitive not only to the living beings but to the entire Nature and environment around us as well. In this way even polluting air, land and water is a violent deed which we must avoid. On being firmly established in non-violence, there is abandonment of hostility in his vicinity. When one is established in non-violence, there develops a kind of magnetism around one that influences anybody who approaches.

Truthfulness: (Satya) means being true to oneself and others. It means being established in truthfulness and increasing accountability for our individual and collective actions.

Honesty: (Asteya) teaches that we should be fair in dealings. We should live not on foul means but on fair means. Secondly if God has blessed us with prosperity and we have enough to help others we must help others. If not, it is just a stealing. We must realize the joy that comes from sharing with others. Life is for sharing and caring. Life is for giving.

Brahmacharya: It refers to celibacy, self-regulation, or self-restraint. It is about developing self-mastery. Veerya means semen, about which it is said that one drop is made out of forty drops of blood. Veerya creates vitality. It is the essence of life which ultimately converts itself into energy. Thus, on being firmly established in brahmacharya, the Yogi gains vigor, energy and courage, whereby he becomes free of the fear of death.

Aparigraha: It stands for non-accumulation or nonpossessiveness. It means giving up the tendency of accumulating objects of utility and enjoyment. It means we don't take more than we need. Mahatma Gandhi said it beautifully: There is more than enough for everyone's need, but not enough for any man's greed.

\section{Niyamas}
a. A cleanliness
b. contentment
c. austerity
d. self-study

e. devotion to God actually forms the basis for a healthy human being and a healthy society [8].

Saucha: It stands for purity or cleanliness, purity of thought, word and deed. When the mind is purified or when mental purity is practiced, one becomes fit to practice cheerfulness, concentration and sense control, and because of mental purity, one is able to see the vision of one's self.

Santosha: It stands for contentment. We should develop a sense of inner abundance, realizing that the real bliss lies not in luxuries but in plain living and high thinking. We should therefore embrace simplicity and avoid discontentment. Unexcelled happiness comes from the practice of contentment.

Tapa: It stands for austerity or penance. By practicing austerities, impurities are destroyed and there comes perfection 
in the body and sense organs. Our life is very precious therefore we should live a life that matters and for this we should master our body and mind.

Svadhyaya: It stands for self-study. It is not about reading a newspaper or magazine. Rather it is about studying oneself. We should regularly go through yogic and spiritual scriptures for our self-observation and self-evolution. By self-observation, union with the desired deity is brought about. We should always contemplate on who am I?

Ishwarapranidhana: It refers to self-surrender. We should surrender ourselves to supreme soul or Supreme consciousness. Success in trance comes by complete resignation to God. Yug rishi Sri Ram sharma Acharya said it beautifully: We should surrender ourselves to the supreme self and supreme ideals to become like the supreme.

Yama gives a momentum to the development of a disciplined society. Yama is basically concerned with the social behavior of an individual. It underlines the social code of conduct for an individual, whereas Niyama underlines the personal code of conduct for an individual. Today persons violating personal and social code of conduct are involved in various self-centered behaviors. They are basically concerned with their own selfish ends and have nothing to do with personal and social values. They are not able to think beyond their selfish ends. The result is what we are witnessing everywhere in society as social diseases and social evils like corruption, crime, cheating, violence, terrorism, rape, sexual harassment etc. our media are over flooded with such news and views. The application of Yama and Niyama can play a major role in eradicating these social evils.

They can lead to motivation and commitment for decisions to devote oneself for the welfare of the individual and society as well. Maharshi Patanjali has described Yama as the great universal vows as they are not limited either by class, creed, time or circumstances. They are the guidelines for how we interact with the outer world. Yama and Niyama help us lead a pure, pious, peaceful and conscious life. Each one of these Yamas and Niyama's can transform us profoundly, as we witness through great figures like Mahatma Gandhi, Yugrishi Sri Ram Sharma Acharya and Martin Luther King Jr. guided by truth, nonviolence and love brought about a major change in society. They built their lives around the very first Yama and that philosophical foundation not only transformed their lives but also continues to touch the lives of millions long after they have passed away.

\section{Asana}

Asana means a state of being in which one can remain physically and mentally steady, calm, quiet and comfortable. Asanas are specific body positions which open the energy channels and psychic centers. Asana is a particular posture which is comfortable and steady. Practice of asana positively affects our body and mind, our life force as well as our creative intelligence. Through the perfection of asanas there comes the capability of bearing the pairs of opposites such as heat and cold. When these pairs of opposites cease to have any impact on the body and mind, they no longer make the mind playful and therefore mind becomes calm and peaceful. In Raja Yoga asanas are practiced developing the practitioner's ability to sit comfortably in one position for an extended length of time, as is necessary during meditation.

\section{Pranayama}

The word pranayama is comprised of two roots: prana and ayama. Prana means vital energy or life force. It is the force which is more subtle than air or oxygen. Ayama means extension or expansion of the dimension of prana. Thus, the word pranayama means extension or expansion of the dimension of prana. Pranayama utilizes breathing to influence the flow of prana in the nadis or energy channels of the pranamaya kosha or energy body. The techniques of pranayama provide the method whereby the life force can be activated and regulated in order to go beyond one's normal boundaries or limitations and attain a higher state of vibratory energy. The practice of Pranayama helps us release tensions and develop a relaxed state of mind. It also balances our nervous system and encourages creative thinking. According to Maharshi Patanjali pranayama helps in unveiling true knowledge from the darkness of ignorance. Thereby covering of light disappears [9]. The fitness of the mind for concentration develops through pranayama [10].

\section{Pratyahara}

Pratyahara means withdrawal of the senses from sense objects. Through the practice of pratyahara i.e. withdrawal of the senses from sense objects, there is the highest mastery over the senses [11].

\section{Dharana}

Dharana means concentration. Dharana helps us develop and extend our powers of concentration [12].

\section{Dhyan}

Dhyan means meditation. Uninterrupted flow of consciousness is called dhyan or meditation [13]. Meditation enables our minds to become calm and peaceful.

\section{Samadhi}

Samadhi stands for trance or ecstasy. That state becomes Samadhi when there is the complete absorption of the individual self with the supreme or universal self. [14] Samadhi is the state in which all the seeds of impressions of present and previous deeds inherent in the mind are completely destroyed. And thus, the flow or waves of the mind are completely destroyed and then the seer is established in his true nature that is truth, bliss and consciousness. Thus, the Raja yoga provides an integral approach for the development of consciousness finally paving the way for Self-realization. 
Transformed individual, the core of social and global transformation

The individual and society are complementary and supplementary to each other. Without healthy individuals, the healthy society is not possible. The healthy and transformed individual, in turn, will build up healthy society without any discrimination of caste, creed, colors etc. Therefore, the desirable personal and ethical values help to purify themselves and to transform society. The individual is constantly engaged in examining one's values. One always bears in mind that moral values bring integrity, contentment and peace and bliss; while immoral values bring confusion, conflicts, miseries and misfortunes. One comes to know that one can choose one's values for a blissful life. Accountable and right actions stem out of proper understanding and adoption of right values. Therefore, the application of yoga for social well-being and social transformation is the need of the hour. When the sun of yoga will shine over the horizon of the world and society today, the social evils, all the immoral and inhuman behavior will disappear, and the dream of a peaceful, prosperous, blissful and transformed society will be fulfilled. Yoga, indeed, immerses a person into the essence of Satyam-Shivam-Sundaram and Satchita-Ananda (Truth-Bliss-and Consciousness) and therefore, the society having such persons is like a heaven on the earth. That is why all the enlightened yogis like Maharshi Aurobindo, Mahrashi Raman, Ramkrishna Paramhansa, Swami Vivekananda, Swami Dayananda Saraswati, Yugrishi Sri Ramsharma Achraya, Swami Shivananda etc gave importance to the global application of yoga and initiated a renaissance among the common masses to eradicate personal and social evils and to create heavenly atmosphere on the earth.

\section{Yoga is for the whole world and humanity}

Yoga works on one's body, mind and soul. Therefore, it is known as the global art. When our body, mind and soul are healthy and harmonious, we will bring health and harmony to the world-not by withdrawing from the world but by being a healthy living organ of the body of humanity. Therefore, yoga is for the whole world and humanity. Human suffering is the same. Whether we are Hindus, Muslims, Christians, Jews or others or whether we are Indian, Italians, Japanese, Chinese or Americans. We all are the humans. Everyone needs physical, mental and spiritual wellbeing for a peaceful, prosperous and blissful life. And yoga in fact, serves this purpose. Afflictions of the body are the same. Afflictions of mind are the same. Diseases and sufferings know no caste, religion or nation, and yoga is given to cure those diseases.Maharshi Patanjali describes yoga as sarvavhauma, that means Universal. Maharshi Patanjali in Yogasutra 2-31 says:

"Jatides kala samayana vachchhinnah sarvbhauma mahavratam"

Which implies that "when practiced universally without exception due to birth, place, time and circumstances they
(Yamas) become great disciplines." [15] It is recommended that, they (Yamas) should be practiced universally without exception. There should be no modification due to differences in country, birth, time, place and circumstances. Thus, yoga is a Universal culture, or it has Universal appeal? Just as it works on the whole of the individual, so it is meant for the development of the whole of mankind on the physical, mental, and spiritual levels. It is yoga which can give permanent solution to these global problems.

\section{Swami Shivananda says}

"Today in this age of atomic armament, racial hatred, intolerance and distrust, the moral, ethical and cultural refinement of the individual personality upon a world-wide scale is to be realized first and foremost. For, the prime and fundamental unit of all wider groups like class, race, nation and human society the world over is the individual man. This is not an impossible proposition, for the divine exists in all beings and it is an integral part of every individual consciousness. The method to draw it out is right and true yoga or spiritual education" [16].

\section{Sri Ram Sharma Acharya observes}

"The dream of the creation of a divine society for the Universal peace, prosperity and bliss can come true only when each one develops divinity within oneself and become a divine and pious human being by refining his thoughts through yoga and spirituality, otherwise there seems to be no other way of permanent and real peace and bliss in the world" [17].

\section{Maharshi Aurobindo very Beautifully Remarks}

"The yoga we practice is not for ourselves alone, its aim is to work out the will of the divine in the world, to effect a spiritual transformation and to bring down a divine nature and a divine life into the mental, vital and physical nature and life of humanity. Its object is not personal mukti or liberation, although mukti is necessary condition of the yoga, but the liberation and transformation of the whole human being" [18].

\section{Swami Ramdev argues}

"All persons in the world want peace and happiness. All the nations of the world agree on this point that peace should be established in the world. Is there a path which can lead to the social and global peace and harmony? Is there a way to achieve complete happiness, peace and bliss in life? This is the path of ashtanga yoga propounded by the great sage Patanjali. This is not a creed, belief or sect; it is a complete method of living life. If the people all over the world are really serious about it that peace must be established in the world, its only solution is- observance of Astanga yoga. It is only through eight-limbed (ashtanga) yoga that personal and social harmony, physical health, mental peace and spiritual bliss can be realized" [19].

\section{Dr. H.R. Nagendra says}

"Yoga is a science of holistic living. It is Universal in its approach and applicable to all human beings irrespective of sex, age, caste, creed or religion. Anyone who wants to raise himself 
from the lowest level to the highest level of human achievement can take to yoga" [20]. One who rises above all narrowmindedness and loves mankind and looks at the whole world like family from the depth of his heart Vasudhaiva Kutumbakam [21] (Panchatantra 5.38) - is a yogi and a real spiritualist. Geographically and nationally we may be different from each other, but we all are humans, we are all one and are the children of one and the same God. Therefore, from the point of view of being God's children, we are all brothers and sisters. This is what yoga teaches us [23-24].

\section{Conclusion}

For the transformation of society and the globe; there must be the transformation of the individual first, since the individual is the basic unit of society, the creation of a transformed society begins with the transformed individuals. The individual and society are complementary and supplementary to each other. Without healthy and purified individuals, the transformation of society is not possible. In Patanjali's Yoga Darshan (yoga philosophy) the Astanga Yoga (eight-fold path of yoga) has been described. In Astanga Yoga, Yama is basically concerned with the social discipline of an individual which underlines the social code of conduct for an individual whereas Niyama underlines the personal code of conduct for an individual. Today persons violating personal and social code of conduct are involved in various antisocial activities as a result of which the society is over flooded with social evils like corruption, crime, cheating, violence, rape etc. the application of the eight fold path of Raj Yoga can play a major role in curbing these social evils, thereby paving the way for the healthy and harmonious society i.e. the transformation of society. Thus, considering a Universal application of yoga we can say that yoga is the need of the day. Thus, yoga and spirituality having potentials for global transformation can play a pivotal role in making the individual, family, society, nation and the world more civilized, sophisticated and enlightened. It should not degenerate into something barbaric or monstrous, but should endorse moral values and ethics, in order that the world we live in could be transformed into a better place.

\section{References}

1. Rigveda-5.5.81.1

2. Atharvaveda-6.91.1

3. Yoga sutra $1 / 2$

4. Yoga sutra $1 / 3$

5. Gita-2/50

6. Yoga sutra $2 / 29$

7. Yoga sutra $2 / 30$

8. Yoga sutra $2 / 32$

9. Yoga sutra $2 / 52$

10. Yoga sutra $2 / 53$

11. Yoga sutra $2 / 55$

12. Yoga sutra $3 / 1$

13. Yoga sutra-. $3 / 2$

14. Yoga sutra $3 / 3$

15. Yoga sutra $2 / 31$

16. Divine Life (2004) Divine Life Society, Rishikesh p. 3

17. Sri Ram sharma Acharya Vangamaya, Samajik, Naitik evam Baudhik, Kranti kaishe? Akhand Jyoti Sansthan, Mathura p.7.9

18. Aurobindo Sri (2005) Yoga and its Objects, Aurobindo Ashram, Pondicherry p. 7

19. Balkrishna Acharya (2010) Yoga Sandesh p. 14

20. Uday (2010) Upali Aparajeeta Path, India, magazine, p. 55

21. Panchatantra-5.38

22. Vivekananda, Swami (2007) Six Lessons on Raja Yoga, Advaita Ashrama, Kolkata p. 7

23. Swami Satyananda Saraswati (2002) Asana Pranayama Mudra Bandha, Yoga Publication Trust, Munger, Bihar, India pp. 361

24. Swami Satyananda Saraswati (2002) Four Chapters on Freedom, Yoga Publication Trust, Munger, Bihar, India pp. 204

Your next submission with Juniper Publishers
will reach you the below assets
- Quality Editorial service
- Swift Peer Review
- Reprints availability
- E-prints Service
- Manuscript Podcast for convenient understanding
- Global attainment for your research
- Manuscript accessibility in different formats
( Pdf, E-pub, Full Text, Audio)
- Unceasing customer service
Track the below URL for one-step submission
https://juniperpublishers.com/online-submission.php

